\title{
Perbedaan antara Metode Pembelajaran Satu Arah dan Role-play terhadap Nilai Obstetri Ginekologi Mahasiswa Fakultas Kedokteran UMM
}

\author{
The difference between one-way learning methods and role-play on the grades of gynecological \\ obstetrics in medical students, University of Muhammadiyah Malang
}

\author{
Kusuma Andriana ${ }^{1}$ \\ ${ }^{1}$ Fakultas Kedokeran Universitas Muhammadiyah Malang, Indonesia \\ *Penulis Korespondensi. Email: Email: andrianakusuma@yahoo.com
}

Telp: +62-81555666621

\begin{abstract}
Abstrak
Latar Belakang: Keterampilan klinis merupakan satu dari 7 area kompetensi pada Standar Kompetensi Dokter Indonesia (SKDI). Model pembelajarannya bisa beragam salah satunya adalah bermain peran (role-play). Program ETLS (Emergency Trauma Life Support) dan CSR (Clinical Skill Refreshment) di FKUMM adalah program persiapan memasuki tahap pendidikan profesi dengan melakukan review dari semua pembelalajaran keterampilan klinis. Institusi sudah melakukan perubahan metode pembelajaran keterampilan klinik dari satu arah ke metode role-play, namun belum pernah dilakukan evaluasi, khususnya pada bagian obstetri ginekologi dengan berbagai keterampilan klinik. Penelitian ini bertujuan mengetahui perbedaan antara metode pembelajaran satu arah dan role-play di program ETLS dan CSR terhadap nilai obstetrik ginekologi pada mahasiswa FKUMM

Metode: Penelitian observasional analitik dengan cara iris silang terhadap nilai ETLS - CSR gelombang 14 dan 15 (metode satu arah) dan gelombang 20 tahap 1 dan 2 (metode role-play) dan nilai kepaniteraan klinik obstetri dan ginekologi dari mahasiswa yang telah mengikuti ETLS-CSR gelombang 14, 15 dan 20 tahap 1 serta 20 tahap 2.

Hasil: Diperoleh nilai rerata, maksimal dan minimal OSCE ETLS-CSR dan kepaniteraan klinik obstetri ginekologi metode role-play lebih tinggi daripada metode satu arah. Hasil uji Mann Whitney nilai ETLS dan CSR station obstetri dan ginekologi dengan $\alpha=0,000$, independent sample $T$ test pada nilai kepaniteraan obstetri dan ginekologi dan didapatkan nilai $\alpha=0,000$, dan uji Wilcoxon Signed Ranks untuk melihat pengaruh pola pembelajaran ETLS-CSR terhadap nilai kepaniteraan klinik obstetri ginekologi dengan nilai $\alpha=0,000$.

Kesimpulan: Terdapat perbedaan bermakna antara metode pembelajaran satu arah dan role-play di program ETLS (Emergency Trauma Life Support ) dan CSR (Clinical Skill Refreshment) terhadap nilai obstetric ginekologi pada mahasiswa FKUMM.
\end{abstract}

Kata Kunci: metode satu arah, metode role-play, keterampilan klinis

\begin{abstract}
Background: Clinical skills are one of the 7 competency areas at the Indonesian Doctors Competency Standards (SKDI). The learning model can be varied, one of which is role play.The ETLS (Emergency Trauma Life Support) and CSR (Clinical Skill Refreshment) program at FKUMM is a preparatory program entering the stage of professional education by conducting a review of all clinical skills learning. FKUMM has changed the method of learning clinical skills from one way to the role-play method in the ETLS and CSR (program, but its impact evaluation has never been done) especially in gynecology obstetrics with many clinical skills. Aim to determine the difference between one-way learning methods and role-play in ETLS and CSR programs on the scores of gynecological obstetrics in FKUMM students

Method: An Analytic observational study with cross sectional method on gradesof ETLS - CSR at groups 14 and 15 (one-way method) and group 20 stages 1 and 2 (role-play method) and grades of on obstetric and gynecology clinics from students who had following ETLS-CSR waves 14, 15 and 20 stages 1 and 20 stages 2

Result: The average, maximal and minimum scores of medical student atETLS-CSR and gynecology obstetric department with role-play were higher than the one-way method. To see the differences in one-way and role-play methods, Mann Whitney tests were performed on obstetrics and gynecology stations at OSCE ETLS and CSR with $\alpha=$ 0,000 , carried out by independent sample T test on student's scores at obstetric and gynecological department with $\alpha=$ 0,000, and the Wilcoxon Signed Ranks test was conducted to see the effect of the ETLS-CSR learning pattern on the student's score at gynecological obstetric department with $\alpha=0,000$.

Conclusion: There were significant differences between the one-way learning and role-play method in the ETLS and CSR program on the scores of medical student at gynecological obstetrics department of University of Muhammadiyah Malang
\end{abstract}

Keywords: one-way learning method, role-play, clinical skills 


\section{PENDAHULUAN}

Kemampuan keterampilan klinis (skill) adalah hal penting dalam pembelajaran pendidikan kedokteran yang dibutuhkan dalam menangani pasien. ${ }^{1}$ Keterampilan klinis merupakan satu dari 7 area kompetensi yang tertuang di SKDI dan diharapkan mahasiswa mampu melakukan prosedur klinis yang berkaitan dengan masalah kesehatan dengan menerapkan prinsip keselamatan pasien, keselamatan diri sendiri, dan keselamatan orang lain. ${ }^{2,3}$ Miller (1990) menyebutkkan ada 4 level penilaian kompetensi klinik terdiri dari knows, knows how, shows how, dan does yang dalam SKDI tersebut sebagai level 1,2,3 dan 4 secara berurutan. ${ }^{4}$

Mahasiswa FK UMM yang telah menyelesaikan pendidikan preklinik akan memasuki tahap pendidikan profesi. Mahasiswa perlu dipersiapkan agar peralihan dari preklinik ke pendidikan profesi berlangsung baik, dan mahasiswa siap menjalani pendidikan profesi di rumah sakit pendidikan FK UMM. Persiapan yang dilakukan adalah dengan membekali mahasiswa dengan suatu program Emergency Trauma Life Support (ETLS) - Clinical Skill Refreshment (CSR). Program ini telah berlangsung lebih dari sepuluh tahun dengan metode pembelajaran yang terakhir adalah pembelajaran satu arah dan dilakukan perubahan menjadi metode role-play pada tahun $2014 .^{5}$

Model pembelajaran bermain peran (role-play) adalah salah satu model strategi pembelajaran aktif yang diperankan oleh mahasiswa seperti drama, simulasi, permainan, demonstrasi kasus dan berbagai hal. ${ }^{6,7}$ Metode ini merupakan satu dari metode pembelajaran orang dewasa (adult learning). Pada metode adult learning dibutuhkan berbagai hal yang saling berterkaitan Intinya dibutuhkan pembelajar yang mempunyai rasa ingin tahu, mandiri, mental sebagai pembelajar, kesiapan untuk belajar, orientasi yang jelas, dan memilki motivasi tinggi untuk belajar. $^{8}$
Metode role-play merupakan salah satu cara belajar yang dapat mengakomodasi berbagai gaya belajar. Pada tahun 1983 David Kolb mengkategorikan proses belajar menjadi feeling (mendapatkan pengalaman konkrit), watching (melakukan observasi dan refleksi), thinking (mengkonsep abstrak) dan doing (aktif melakukan eksperimen). Kombinasi dari proses menghasilkan 4 gaya belajar yaitu Accomodating yaitu proses feeling dan doing, diverging yaitu proses feeling dan watching, assimilating yaitu proses thinking dan watching dan converging yaitu thinking dan doing Role-playing merupakan alat bantu untuk berbagai gaya belajar sehingga mahasiswa dapat mempraktekqn feeling, watching, thinking dan doing dari skenario yang ada. ${ }^{9}$

Selama 4 tahun pelaksanaannya belum pernah dilakukan evaluasi dampak perubahannya terutama perubahan nilai mahasiswa. Penelitian ini bertujuan mengetahui perbedaan antara metode pembelajaran satu arah dan role-play di program ETLS dan CSR terhadap nilai obstetrik ginekologi pada mahasiswa FK UMM.

\section{METODE}

Penelitian ini merupakan penelitian observasional analitik dengan cara iris silang (cross sectional). Tujuannya untuk mengetahui perbedaan antara metode pembelajaran satu arah dan role-play di program ETLS dan CSR terhadap nilai obstetrik ginekologi pada mahasiswa FK UMM. Sampel adalah data nilai ETLS - CSR gelombang 14 dan 15 (metode satu arah) dan gelombang 20 tahap 1 dan 2 (metode roleplay ) dan data nilai kepaniteraan klinik obstetri dan ginekologi dari mahasiswa yang telah mengikuti ETLS-CSR gelombang 14, 15 dan 20 tahap 1 serta 20 tahap 2. Analisis statistik yang dilakukan adalah independentsample $\mathrm{T}$ test untuk membandingkan rerata dua kelompok sampel independen bila 
sebaran data normal. Bila sebaran data tidak normal, akan dilakukan tranformasi data, dan bila sebaran data tetap tidak normal akan dilakukan uji non parametrik dengan uji Mann Whitney. Paired T test dilakukan pada sebaran data yang normal untuk membandingkan rerrata dua kelompok sampel yang saling berhubungan, Bila sebaran tidak normal akan dilakukan uji non parametrik dengan Wilcoxon Signed Ranks test. ${ }^{10}$

Dari data deskriptif tabel 1 dan 2 diperoleh rerata nilai, nilai maksimal dan nilai minimal OSCE ETLS-CSR dan kepaniteraan klinik obstetri ginekologi dengan metode role-play lebih tinggi daripada metode satu arah. Untuk melihat perbedaan metode satu arah dan roleplay dilakukan uji Mann Whitney pada nilai ETLS dan CSR station obstetri dan ginekologi, diperoleh nilai $\alpha=0,000$ (< 0,005), kemudian dilakukan independent sample $\mathrm{T}$ test pada nilai kepaniteraan obstetri dan ginekologi dan didapatkan nilai $\alpha=0,000(<0,005)$ dan dilakukan uji Wilcoxon Signed Ranks untuk melihat pengaruh pola pembelajaran ETLS-CSR terhadap nilai kepaniteraan klinik obstetri ginekologi dan diperoleh nilai $\alpha=0,000(<$ 0,005).

Tabel 1. Data nilai OSCE ETLS-CSR obstetri dan ginekologi

\begin{tabular}{lccccc}
\hline ETLS-CSR & N & Rerata Nilai & $\begin{array}{c}\text { Nilai } \\
\text { Maksimal }\end{array}$ & $\begin{array}{c}\text { Nilai } \\
\text { Minimal }\end{array}$ & $\begin{array}{c}\text { Simpangan } \\
\text { Baku }\end{array}$ \\
\hline Pola Lama & 63 & 52,74 & 78,13 & 30,00 & 10,09 \\
Pola Baru & 79 & 62,68 & 93,00 & 28,50 & 17,26 \\
\hline
\end{tabular}

Sumber : data primer

Tabel 2. Data nilai kepaniteraan klinik obstetri dan ginekologi

\begin{tabular}{lccccc}
\hline ETLS-CSR & N & Rerata Nilai & $\begin{array}{c}\text { Nilai } \\
\text { Maksimal }\end{array}$ & $\begin{array}{c}\text { Nilai } \\
\text { Minimal }\end{array}$ & $\begin{array}{c}\text { Simpangan } \\
\text { Baku }\end{array}$ \\
\hline Pola Lama & 63 & 68,03 & 78,13 & 58,11 & 3,81 \\
Pola Baru & 79 & 75,25 & 85,59 & 65,91 & 3,6 \\
\hline
\end{tabular}

Sumber : data primer

Untuk mengetahui apakah terdapat pengaruh pola pembelajaran di ETLS-CSR terhadap nilai kepaniteraan klinik obstetri ginekologi dilakukan uji nonpramaterik dg Wilcoxon Signed Ranks test. Terdapat 22 sampel yang mengalami penurunan nilai (negative ranks) dengan selisih rerata penurunannya 42,81 point, sementara terdapat 120 sampel yang mengalami peningkakatan nilai (positive ranks) dengan selisih rerata peningkatannya adalah 80,15 ponit. Hasil ujistatistik diperoleh $\alpha: 0,000$ (< 0,05), sehingga disimpulkan terdapat perbedaan yang bermakna antara nilai kepaniteraan klinik obstetri ginekologi pada mahasiswa dengan metode ETLS-CSR metode sartu arah dan metode role-play.

\section{PEMBAHASAN}

Setiap dokter diharapkan kompeten melakukan pemeriksaan klinis. Diberlakukannya SKDI merupakan upaya untuk menstandarkan kompetensi lulusan dokter Indonesia dari sisi keilmuan, keterampilan klinis dan sebagainya.2 Fakultas Kedokteran UMM mengupayakan pembekalan mahasiswa yang akan melanjutkan pendidikan profesi dengan 
menjalani program ETLS-CSR. Dirasa perlu melakukan perubahan metode pembelajaran keterampilan klinik (skill), sehingga metode satu arah yang dilakukan kemudian berganti menjadi metode role-play. Bentuk kegiatan ETLS dan CSR periode sebelumnya adalah pemberian materi dengan mereview semua skill kompetensi 4 yang diberikan satu arah, kemudian dilakukan perubahan terutama pada review pembelajaran skill, yaitu dilakukan dengan role-play.

Pada sistem ini mahasiswa secara berkelompok akan dilatih untuk menyelesaikan kasus-kasus panjang seperti Ujian Kompetensi Mahasiswa Program Profesi Dokter (UKMPPD). Diakhir kegiatan ETLS-CSR, akan dilakukan evaluasi dalam bentuk Objectve Structure Clonical Examination (OSCE). ${ }^{5}$

Keterampilan klinis obstetri dan ginekologi di SKDI didapatkan cukup banyak dan bervariasi sehingga diperlukan pemahaman yang baik dari keterampilan obstetri ginekologi ini. ${ }^{2}$

Hasil dari penelitian ini menunjukkan perbedaan rerata nilai yang bermakna antara pola lama (metode satu arah) dan pola baru (metode role-play ) Di program ETLS-CSR maupun nilai kepaniteraan klinik obstetri dan ginekologi. Hal ini sejalan dengan Acharya,et al (2014) yang menyebutkan bahwa role-play merupakan metode yang efektif untuk pembelajaran di FK. Acharya, et al (2014) melakukan penelitian terhadap 24 mahasiswa FK tingkat akhir yang dibagi menjadi 3 kelompok yaitu kelompok sistem kardiovaskular, sistem respirasi dan sistem abdomen yang melakukan serial role-play. Selama 2 bulan dilakukan pemberian presensitisasi berupa kasus-kasus singkat yang di ranah kognitif, afektif dan psikomotor setelah itu kemudian dilanjutkan post sensitisasi dengan skenario yang akan diperankan. Didapatkan perubahan yang bermakna pada kognitif, afektif dan psikomotor sampel. ${ }^{11}$

Penelitian ini juga sejalan dengan Nestel \& Tierney, (2007) yang menyatakan bahwa role-playmerupakan metode yang sangat membantu untuk skill komunikasi walaupun sampel belum pernah memiliki pengalaman untuk melakukan sebelumnya. Dalam penelitiannya, Nestel \& Tierney (2007) mengambil 284 sampel mahasiswa tahun pertama untuk mengikuti program skill komunikasi. Sebelum dan sesuah penelitian, sampel diminta untuk mengisi kuesioner, dan diperoleh $22,2 \%$ yang menjawab bahwa roleplay tidak membantu pembelajaran,sementara 96,5 \% lainnya merasa terbantu. ${ }^{12}$ Kunci yang berperan dalam keberhasilan role-play adalah adanya panduan yang memadai, kejelasan peran dan tugas selama kegiatan, adanya umpan balik dan interaksi antara fasilitator dan mahasiswa., dan adanya evaluasi terhadap simulasi yang sudah dijalankan. ${ }^{13}$

Berbeda dengan Stevenson, et al (2002) yang melakukan penelitian role-play menggunakan kwesioner pada 195 mahasiswa FK, 128 mahasiswa bidang bisnis dan 72 mahasiswa psikologi. Semuanya adalah mahasiswa yang baru menjalani pendidikannya di minggu pertama di universitas. Diperoleh hasil bahwa metode ini 75\% tidak efektif karena di tahun pertama, mahasiswa FK masih belum siap dengan sistem student centered learning, sementara $54 \%$ mahasiswa bisnis dan $22 \%$ mahasiswa psikologi mengatakan pembelajaran ini tidak bermanfaat. ${ }^{14}$

$$
\text { Vogel D \& Sigrid H (2016) }
$$
melakukan revieuw terhadap 43 hasil penelitian teknik pembelajaran skill dengan role-play. ${ }^{1}$ Hasil OSCE menunjukkan nilai lebih baik pada metode role-play, mahasiswa yang menggunakan multimedia untuk pembelajarannya, mahasiswa yang mendapat simulasi sebelumnya, mahasiswa yang diberikan feed back Sementara tidak 
diperoleh perbedaan nilai pada mahasiswa dengan fasilitator yang dokter umum atau spesialis. Kelompok role-play optimal adalah 1 fasilitator mendapingi 4 mahasiswa. ${ }^{9,15}$ Kelemahan penelitian karena hanya memilih 2 periode pola lama dan 1 periode baru, yang belum dapat menggambarkan secara detail hasil pembelaharan metode role-play.

\section{KESIMPULAN}

Terdapat perbedaan yang bermakna antara metode pembelajaran satuarah dan role-play di program ETLS dan CSR terhadap nilai obstetri ginekologi pada mahasiswa FK UMM.

\section{DAFTAR PUSTAKA}

1. Daniela V, Heredza S. Basic practical skills teaching and learning in undergraduate medical education - a review on methodological evidence. GMS. Journal for Medical Education. 2016, 33(4), 1-19.

2. Konsil Kedokteran Indonesia. Standar kompetensi dokter Indonesia. 2012

3. Fitri AD. Penerapan problem based learning (PBL) dalam kurikulum berbasis kompetensi. JMU. 2015, 4(1), 95-100.

4. Zulharman. Perancangan Objective Structured Clinical Examination (OSCE ) untuk Menilai Kompetensi Klinik. JIK. 2011, 5(1), 7-12.

5. FKUMM. Buku Kegiatan Emergency Trauma Life Support )dan CSR (Clinical Skill Refreshment). 2014

6. Erturk E. Evaluation of Role Play as a Teaching Strategy in a Systems Analysis and Design Course. International Journal of Learning. 13x(November). 2015a. 150-159. Retrieved from https://www.researchgate.net/publicatio n/284285165

7. Erturk E. Role Play as a Teaching Strategy, (October). 2015b. http://doi.org/10.13140/RG.2.1.4287.94 49
8. Konwles MS, Holton EF, Swanson RA. The Adult Learner 6th ed. Amsterdam: Elsevier Ltd. 2005

9. Suen W, Hughes J, Russell M. From Role-playing To Real-playing: Teaching Effective Facilitation Skills, (June), 2011, 1-27.

10. Sopiyudin MD. Statistik untuk kedokteran dan kesehatan, deskriptif, bivariat, dan multivariat dilengkapi aplikasi menggunakan SPSS, Cet.ke-4, Epidemiologi Indonesia, 2016, pp:1-28.

11. Acharya S, Shukla S, Acharya N, Vagha J. Role play - an eff ective tool to teach clinical medicine. 2014, 2(2). http://doi.org/10.5455/jcme.2014061911 1139

12. Nestel D, Tierney T. Role-play for medical students learning about communication: Guidelines for maximising benefits. 2007, 9, 1-9. http://doi.org/10.1186/1472-6920-7-3

13. Kneebone R. Evaluating Clinical Simulations for Learning Procedural Skills: A Theory-Based Approach. Academic medicine. Journal of the Association of American Medical Colleges. 2005, 80. 549-53. 10.1097/00001888-200506000-00006.

14. Stevenson K, Sander P, Stevenson K, Sander P. Medical students are from Mars business and psychology students are from Venus University teachers are from Pluto. 2002. 24(1), 27-31. http://doi.org/10.1080/ 00034980120103441

15. Moulton CAE, Dubrowski A, MacRae H, Graham B, Grober E, Reznick R. Teaching Surgical Skills: What Kind of Practice Makes Perfect? Transactions of the Meeting of the American Surgical Association. 2006, 124,6675.doi:10.1097/ $01 . \quad$ sla. 0000234808.8578 